\title{
Families 'experiences to Find a Job for Relatives who Have Severe Mental Illness in
} Iran: A Qualitative Study

\section{Mehdi Rassafiani', Mitra Khalafbeige ${ }^{2 *}$, Farahnaz Mohammadi Shahboulaghi ${ }^{3}$, Hojjat-allah Haghgoo ${ }^{4}$, Hamid Taherkhani ${ }^{5}$}

1. Associate Professor, Department of Occupational Therapy, Faculty of Rehabilitation Sciences, University of Social Welfare and Rehabilitation Sciences, Tehran, Iran

2. Assistant Professor, Department of Occupational Therapy, School of Rehabilitation, Iran University of Medical Sciences, Tehran, Iran

3. Associate Professor, Social Determinants of Health Research Center, University of Social Welfare and Rehabilitation Sciences, Tehran, Iran

4. Associate Professor, Department of Occupational Therapy University of Social Welfare and Rehabilitation Sciences, Tehran, Iran

5. Psychiatrist, Tolo Rehabilitation Center, Tehran, Iran

\begin{tabular}{l}
\hline Article Info \\
\hline Received: $2017 / 03 / 28$ \\
Accepted: $2017 / 06 / 05$ \\
Published Online: 2017/10/29 \\
DOI: \\
10.30699/fdisj.01.1.40 \\
How to Cite This Article \\
Rassafiani M, Khalafbeige \\
M, Mohammadi Shahbou- \\
laghi F, Haghgoo H, Ta- \\
herkhani H. Families 'ex- \\
periences to Find a Job for \\
Relatives who Have Severe \\
Mental Illness in Iran: A \\
Qualitative Study. Func Dis- \\
abil J. 2018; 1 (1) :40-48 \\
Use your device to scan and \\
read the article online
\end{tabular}

\section{ABSTRACT}

Background and Objectives: Families of people with severe mental illness may provide different facilities according to the context they are living in. This study aimed to explore the experience of families in the process of finding a job for their mentally ill relatives in Iranian context whose social support appears to be less than that of developed countries.

Methods: 19 participants (10 people with severe mental illness, 7 family members, 2 psychiatrists and one supervisor who recruited a mentally ill worker) took part in this qualitative study, where data was analyzed through content analyses approach.

Results: Organizing the current situation" and "neglecting the key points" were the two main themes extracted from the study.

Conclusion: In Iran, family network has a strong control over the job finding process. Moreover, the limitation in social supports entails families selecting multiple strategies for helping their relatives

Keywords: Vocation, Employment, Severe mental illness, Family

Corresponding Information:

Mitra Khalafbeige, Assistant professor, Department of Occupational Therapy, School of Rehabilitation, Iran

University of Medical Sciences, Tehran, Iran. Email: ot_mitra@yahoo.com

Copyright (C) 2018, Function and Disability Journal. This is an open-access article distributed under the terms of the Creative Commons Attribution-noncommercial 4.0 International License which permits copy and redistribute the material just in noncommercial usages, provided the original work is properly cited.

\section{Introduction}

Work is recognized as a route to recovery for the mentally ill as it brings them many financial and nonfinancial advantages (Boardman et al., 2003). Employment of people with mental health problems not only can elevate their quality of life (Marwaha et al. 2008), but also might provide some monetary benefits for the society they are living in(Gilbert et al., 2013).Given the critical role of employment with regards to such people, certain measures have been taken in developed countries. For instance, in the US, mental health ser- vices have allocated a high priority to the employment of people with Severe Mental Illnesses (SMI) (Marwaha et al., 2009).Similarly, the political agenda in the UK has covered the employment of mentally ill clients and tried to modify the welfare benefit systems(Blank et al., 2011).

However, the policies or facilities of developed countries may not be applicable to developing ones. For instance, the most extensively evaluated service is Individual Placement and Support (IPS), yet it has been proved, via research, to be effective in the U.S, 
Canada, Brazil and Australia (Fossey, 2010). Another example is "Work incentive" which is financial facilities for mental disabilities provided by the Social Security Administration (SSA) in the USA (Liberman, 2009). In Iran, as a developing country, work programs are limited to modified sheltered workshops and such services as IPS and SSA are yet to be developed.

In such conditions, factors like "family" may become prominent as far as a finding job for patients with SMI. In general, families often exert positive influence on career development (Isik, 2013). Researches suggest that families of people with SMI can facilitate the job finding process (Drapalski et al., 2009). In fact, family support can be considered as a positive and enabling factor regarding people with mental health issues (Tse 2002). Dunn et al (2010) found that families try to convey a positive feeling to their mentally ill relatives or assist them in finding and sustaining a job. Similarly, Alverson (2006) revealed that certain families can act as either a job seeker or a sponsor for their relatives. In contrast, Henry (2004) indicated that families may prevent their relatives from getting back to work, as they are afraid their patients may either lose disability payments, or might not be capable enough to work. Ergo, says the roles of the family and their experiences in job finding do not seem homogenous.

Moreover, given the different policies in the West and East, the kind and amount of families' experiences may differ. While in developing countries social support is partial (Ohaeri, 2001), Western families are under subtle consideration by their governments and their burdens, needs, perceptions, life styles and other issues are considered (van Wijnagarden et al. , 2000). Furthermore, due to the dominance of strong family relationships, particularly in Iran, most of the patients may receive extra support from their caregivers (Khalafbeigi et al., 2015). Besides, due to the absence of common vocational services in Iran, families are under more pressure when finding a job for their patients, hence their experience may represent certain diversities.

Some studies have explored the benefit of family involvement in job finding, however; the details of such involvement, have not yet been investigated. Also, quantitative researches have mostly focused on the efficacy of specific approaches, IPS in particular, regarding employment (Blank et al., 2011). Finally, most qualitative studies have explored service users' perspectives (For example, Woodside et al. 2006, Huff et al. 2008; Boo et al., 2011), or service providers' views(For instance, Blitz 2005, Lemieux et al. 2011) or both(Henry, 2004)without accounting for the experiences of families. Given the holistic approach of occupational therapy, it is necessary that our practice be focused on the complicate dynamics among the client, family and community. Therefore, the aim of the present study was to explore the experience of Iranian families during the job finding process in the absence of a rich social support.

Considering the high unemployment rate of people with SMI \{e.g., Australia: 78\%, France: $88.5 \%$, Germany: 70\% (Harvey et al., 2013), Iran: 70\% (Nabdel et al., 2002) $\}$ and its economic impact on the society, exploring the effect of family's role can provide useful information for service providers, even in countries with various services provided for the mentally disabled.

\section{Material and Methods}

Using latent content analysis, a qualitative approach (Graneheim, 2004) was employed in the present research. Participants included ten people with SMI who had been receiving outpatient mental health services, seven family members, two psychiatrists and one supervisor who recruited a mentally ill worker.

The characteristics of the participants are depicted in Table 1 and 2.

The recruited patients had a job experience of at least six months or were looking for a job, above the age of 18. These patients were at the chronic phase of their illness (according to medical records) and were willing to participate in the study and had the ability to communicate with the interviewer. Other participants (family members, psychiatrists and the supervisor) had experience or expertise in the process of job finding for people with SMI.

Data was collected through semi-structured inter- 
views. In the beginning, participants were asked openended, general questions about the role and position of the families as far as job finding was concerned: "How did your family act when you were looking for a job?", "What problems did you (family member) face when finding a job for your ill relative?" were among the asked questions. These questions became more focused through following and probe questions such as, "Explain more" or "What do you mean exactly?"

Interviews lasted from 13 to 60 minutes. Prior to the interview, a written informed consent was obtained from the participants. The time and place of the interviews were agreed by both parties. The participants had the right to leave the study at any time and contact the interviewer if they had any questions about the study. Recorded interviews were kept in safe, password protected files.

Interviews were transcribed and analyzed using qualitative latent content analysis which involved reading the texts several times so as to obtain a sense of the whole, selecting the meaning units, making them condensed and abstracted and labeling them with a code. Next, the codes were compared with regard to differences and similarities, subcategorized and finally categorized. The credibility of the data was determined through maximum variation in sampling, peer check, external check, memoing and prolonged engagement with the participants and data.

\section{Results}

Based on the participants' experiences, two main themes were identified: "organizing the current situation" and "neglecting the key points".

Participants' quotes were presented along with the description of the categories.

\section{Organizing the Current Situation}

This category indicates the strategies used by families to manage and speed up the job finding process. Subcategories include: becoming an employer, financial and emotional support and searching for information and resources.

\section{Becoming an Employer}

Families who thought their relatives were not able to find a job on their own or probably were not fit for working, tried to set up family businesses and become their supervisor.

A patient's sister stated:

"I bought six sewing machines and had my brother work with one of them..... Of course I tried to give him the simplest patterns....His salary was per hours, like other workers...” (Participant 4).

A psychiatrist said:

"I see that many families prefer to set up a family business or take them (relatives) to their own work place. I remember a case where the father had a grocery store and had his son work for him, the results of which were wonderful (Participant 5).

\section{Financial and Emotional Support}

Financial and emotional support was the most highly employed strategy. Families tried to motivate their relatives by mentioning the existence of a bright future, and inspiring the sense of empowerment, and to prevent unemployment by putting them under emotional pressure and providing financial contribution during the job finding. One patient said:

"I wanted to sell some of my paintings in a series of exhibitions, yet my family knew that and bought them from me. They wanted to help me, of course. My cousin bought my paintings at even a higher price!"(Participant 2).

The father of a patient stated:

"He loves driving and always likes to work in a car rental agency as a driver, so I bought a new car for him and pushed him down that road"(Participant 12).

\section{Searching for Information and Resources}

Most families tried to introduce their relatives to their own workplace. Some explored special facilities (like various payments). Others tried to receive information from certain sources (for example, their regional Ministry of Labor or the psychiatric team). A psychiatrist said:

“...actually we see the hierarchy of needs in many patients. When they get better step by step, families alter their needs.....and ask us, 'doctor, do you know any place for work? Do you know any job 
43. Families 'experiences to Find a Job for Relatives ...

positions?"'(Participant8).

A mother who was a psychologist and worked in a psychiatric hospital declared:

"I spoke with the head nurse of our unit and asked her to find a light work for my daughter here....you know she (the daughter) graduated from midwifery school....I also asked our social worker what the best job might be for her"'(Participant 14).

\section{Ignoring the Key Points}

Although most families tried to manage the process of job finding, some neglected the important points which could facilitate the situation. Subcategories include: ignoring patient's preferences and ignoring the therapeutic comments.

\section{Ignoring Patient's Preferences}

Some families found a job or refused or postponed some job opportunities without considering their relative's interest or abilities. Some did not provide any kind of support. A patient said:

"I never had the opportunity to ask my mom what it (work) was. I did not find any chance to ask how much the salary was. My dad merely told me to go (to work) in the morning and comeback in the afternoon for lunch "(Participant 19).
Another patient said:

"My sister told my Mom: 'don't push him to find a work, he is sick, he is not able to have a job. Let him be in his own world!'......For years I tried to have a job but no body, nobody even told me how. I was totally forgotten" (Participant3).

\section{Ignoring the Therapeutic Comments}

Sometimes families rejected the therapeutic advices. For example, they manipulated the dosage of the prescriptive drugs to control the side effects or found a job without any consultation with a team member. A patient's spouse, who ignored the doctor's orders, said:

"At his previous work, he had conflicts with others so we took him to the doctor. The doctor gave him some pills and he slept for one week! We had a lot of issues, so I didn't let him take them anymore. As he is very nervous, he hasn't been able to find any job so far “(Participant 17).

Also, a father whose son could never have a job said:

"His doctor said that he can't do much work, but I do not agree.... we didn't consult with him (doctor) regarding the job finding process anymore... .’(Participant7).

Table 1. demographic characteristic of participants (patients)

\begin{tabular}{|c|c|c|c|c|c|c|c|c|}
\hline \multirow{2}{*}{$\begin{array}{l}\text { Participants, } \\
\text { number }\end{array}$} & \multirow{2}{*}{ Diagnosis } & \multirow{2}{*}{$\begin{array}{l}\text { Gen- } \\
\text { der }\end{array}$} & \multirow[b]{2}{*}{ Age } & \multirow{2}{*}{ Education } & \multirow{2}{*}{$\begin{array}{l}\text { Marital } \\
\text { Status }\end{array}$} & \multirow{2}{*}{$\begin{array}{l}\text { Current work } \\
\text { status }\end{array}$} & \multicolumn{2}{|c|}{ Work history } \\
\hline & & & & & & & $\begin{array}{c}\text { Before onset } \\
\text { of illness }\end{array}$ & $\begin{array}{c}\text { After onset } \\
\text { of illness }\end{array}$ \\
\hline 1 & Schizophrenia & Male & 30 & Master & Single & employed & No & Yes \\
\hline 2 & Schizophrenia & Male & 50 & Associated degree & Single & Unemployed & Yes & Yes \\
\hline 3 & Schizophrenia & Male & 50 & Master & Married & Unemployed & Yes & Yes \\
\hline 9 & Bipolar & Male & 33 & Diploma & Single & Unemployed & No & yes \\
\hline 10 & Bipolar & Male & 32 & Diploma & Married & Unemployed & yes & yes \\
\hline 13 & Bipolar & Female & 24 & Associated degree & Single & Unemployed & No & No \\
\hline 15 & Schizophrenia & Female & 40 & Master & Single & employed & yes & yes \\
\hline 16 & Bipolar & Male & 37 & illiterate & Married & $\begin{array}{l}\text { Unemployed } \\
\text { (receiving assur- } \\
\text { ance disability } \\
\text { payment }\end{array}$ & yes & yes \\
\hline 18 & Schizophrenia & Male & 54 & Diploma & Married & $\begin{array}{l}\text { Unemployed } \\
\text { (receiving assur- } \\
\text { ance disability } \\
\text { payment) }\end{array}$ & yes & Yes \\
\hline 19 & Schizophrenia & Male & 40 & Diploma & Single & Unemployed & No & Yes \\
\hline
\end{tabular}


Table 2. demographic characteristic of participants(family members, psychiatrists and the supervisor)

\begin{tabular}{cccc} 
Participants, number & Position & Age & Education \\
\hline 4 & Sister & 45 & Diploma \\
5 & Psychiatrist (Male) & 60 & Doctorate \\
\hline 6 & supervisor & 57 & Diploma \\
\hline 7 & Father & 54 & Diploma \\
\hline 8 & Psychiatrist (Female) & 42 & Doctorate \\
11 & Spouse (Female) & 30 & Diploma \\
12 & Father & 70 & illiterate \\
14 & Mother & 35 & Master \\
\hline 17 & Spouse (Female) & 31 & Secondary School \\
\hline
\end{tabular}

\section{Discussion}

Results showed that most of the families emphasized on the importance of work. It is best if the work and person are both considered (Whiston 2004). If families focus merely on the financial dimension of the work or have high expectations from their relatives, they may unintentionally impose a lot of pressure on them. In such cases, individuals probably pursue job opportunities just for the income (Rosso et al. 2010). In contrast, positive attitudes toward people's abilities can motivate them in job finding (Killeen 2004). Therefore, family psycho-education programs could be helpful for modifying families' attitudes and strategies in finding a job. Given the fact that families of people with SMI experience burden and distress (Martens 2001) and they consider their patient's unemployment as the most negative issue(Harvey et al. 2001), and due to the relation between vocational outcomes and the impact of illness on family members (Corbière et al 2015), more attention should be given to such programs.

Results also depicted that family support often puts pressure on the process of job finding, which is in contrast to Corbière et al (2011) findings. They found that the more support patients receive, the less time they spend at work, because they consider the family as a solution for all problems and consequently lose their autonomy. Rossoet al (2010), however, stated that when families provide a supportive and pleasant environment or encourage the individuals' efforts, the patient pursue their work goals more confidently.
The cooperation of families and patients reinforces the "worker role" in the latter (Kennedy-Jones et al. 2005). The family protection or so-called "natural support" can facilitate vocational outcomes regardless of the job place the clients are working in. (Vilotti et al 2017) Lack of support entails a situation where despite verbal intention toward having a job, patients deal with the job finding process passively (Alverson et al. 2006).

Such conflicts can be explained in terms of the kind of support; when the family plays the dominant role, the patient experiences ambivalence towards their choice and family priorities (Alverson et al. 2006). Since people with SMI have difficulties in judgment and decision making, such ambivalence may exacerbate the condition. Achieving the best results from vocational programs, a relative balance between family support and patients' independence through family education programs seems necessary.

The strategies used by Iranian families seem similar to those of other countries, except for the variations these strategies indicate. The findings are most similar to Dunn et al. (2010). Although, in both contexts, emotional support and family businesses are detectable, our participants did not believe in the patients' potency, and that is why they went for family businesses. In Dunn's study, nonetheless, families thought that more flexibility was present in family businesses .

The limitation of our study was that among the patients, only two had a job; others either lost their job or did not have any. It would have been better to take 
in more employed patients to add more credibility, yet that was not possible during the study. Moreover, negative cases were not included in the study.

\section{Conclusion}

Despite the small number of families enrolled in the community mental health services (Drapalski, Leith et al. 2009), the role of the family is much more impressive in the Iranian context. Moreover, the limited social support entails families to have multiple strategies to help their relatives. Regarding the issue that some usual services like IPS are not practical for

\section{References}

Alverson, H., E. Carpenter and R. E. Drake (2006). An ethnographic study of job seeking among people with severe mental ill-ness. Psychiatric Rehabilitation Journal, 30(1): 15 .

Blank, A., P. Harries and F. Reynolds (2011). Mental health service users' perspectives of work: A review of the literature. The British Journal of Occupational Therapy, 74(4): 191-199.

Blitz, C. L. and D. Mechanic (2005). Facilitators and barriers to employment among individuals with psychiatric disabilities: a job coach perspective. Work (Reading, Mass.) 26(4): 407-419.

Boardman, J., B. Grove, R. Perkins and G. Shepherd (2003). Work and employment for people with psychiatric disabilities. The British Journal of Psychiatry, 182(6): $467-468$.

Boo, S.-L., J. Loong and W.-S. Ng (2011). Work experiences of people with mental illness in Malaysia: A preliminary qualitative study. The Qualitative Report, 16(1): 162-179.

Corbière, M., Renard, M., St-Arnaud, L., Coutu, M.-F., Negrini, A., Sauvé, G., \& Lecomte, T. (2015). Union perceptions of fac-tors related to the return to work of employees with depression. Journal of occupational rehabilitation, 25(2), 335-347.

Corbière, M., S. Zaniboni, T. Lecomte, G. Bond, P.-Y. Gilles, A. Lesage and E. Goldner (2011). Job acquisition some clients, (Milton et al. 2015) the role of family becomes more sensitive.

\section{Acknowledgments}

This article is based on a thesis written by the corresponding author in partial fulfillment of the requirements for the $\mathrm{PhD}$ degree in Occupational Therapy from the University of Social Welfare and Rehabilitation Sciences.

\section{Conflict of Interest}

Authors declared no conflict of interest.

for people with severe mental illness enrolled in supported employment programs: A theoretically grounded empirical study. Journal of occupa-tional rehabilitation, 21(3): 342-354.

Drapalski, A., J. Leith and L. Dixon (2009). Involving families in the care of persons with schizophrenia and other serious mental illnesses: History, evidence, and recommendations. Clinical Schizophrenia \& Related Psychoses, 3(1): 39-49.

Dunn, E. C., N. J. Wewiorski and E. S. Rogers (2010). A qualitative investigation of individual and contextual factors associated with vocational recovery among people with serious mental illness. American Journal of Orthopsychiatry, 80(2): 185.

Fossey, E. M. and C.A. Harvey (2010). Finding and sustaining employment: a qualitative meta-synthesis of mental health con-sumer views. The Canadian Journal of Occupational Therapy, 77(5): 303.

Gilbert, E., Marwaha, S., Milton, A., Johnson, S., Morant, N., Parsons, N., Cunliffe, D. (2013). Social firms as a means of vo-cational recovery for people with mental illness: a UK survey. BMC health services research, 13(1), 270.

Graneheim, U. H. and B. Lundman (2004). Qualitative content analysis in nursing research: concepts, procedures and measures to achieve trustworthiness. Nurse education today 24(2): 105-112.

Harvey, K., T. Burns, T. Fahy, C. Manley and T. Tattan 
(2001). Relatives of patients with severe psychotic illness: factors that influence appraisal of caregiving and psychological distress. Social Psychiatry and Psychiatric Epidemiology, 36(9): 456-461.

Harvey, S. B., M. Modini, H. Christensen and N. Glozier (2013). Severe mental illness and work: What can we do to maximise the employment opportunities for individuals with psychosis? Australian and New Zealand Journal of Psychiatry, 47(5): 421-424.

Henry, A. D. and A. M. Lucca (2004). Facilitators and barriers to employment: the perspectives of people with psychiatric disa-bilities and employment service providers. Work 22(3): 169-182.

Huff, S. W., C. A. Rapp and S. R. Campbell (2008). Every day is not always Jell-O: A qualitative study of factors affecting job tenure. Psychiatric Rehabilitation Journal, 31(3): 211.

Isik, E. (2013). Perceived Social Support and Locus of Control as the Predictors of Vocational Outcome Expectations. Educa-tional Sciences: Theory \& Practice 13(3): 1426-1430.

Kennedy-Jones, M., J. Cooper and E. Fossey (2005). Developing a worker role: Stories of four people with mental illness. Aus-tralian Occupational Therapy Journal, 52(2): 116-126.

Khalafbeigi, M., F. Mohammadi Shahboulaghi, M. Rassafiani, H.-A. Haghgoo and H. Taherkhani (2015). The meaning of work in people with severe mental illness (SMI) in Iran. Medical Journal of The Islamic Republic of Iran (MJIRI) 29: 179

Killeen, M. B. and B. L. O'day (2004). Challenging expectations: how individuals with psychiatric disabilities find and keep work. Psychiatric Rehabilitation Journal, 28(2): 157.

Knapp, M., R. Mangalore and J. Simon (2004). The global costs of schizophrenia. Schizophrenia bulletin, 30(2): 279.

Lemieux, P., M.-J. Durand and Q. N. Hong (2011). Supervisors' perception of the factors influencing the return to work of work-ers with common mental disorders. Journal of occupational rehabilitation, 21(3): 293-303.
Liberman, R. P. (2009). Recovery from disability: Manual of psychiatric rehabilitation, Washington, DC: American Psychiatric Pub.

Martens, L. and J. Addington (2001). The psychological well-being of family members of individuals with schizophrenia. Social psychiatry and psychiatric epidemiology, 36(3): 128-133.

Marwaha, S., S. Johnson, P. Bebbington, M. C. Angermeyer, T. Brugha, J.-M. Azorin, R. Kilian, A. Kornfeld, M. Toumi and E. S. Group (2008). Correlates of subjective quality of life in people with schizophrenia: findings from the EuroSC study. The Journal of nervous and mental disease, 196(2): 87-94.

Marwaha, S., S. Johnson, P. E. Bebbington, M. C. Angermeyer, T. S. Brugha, J.-M. Azorin, R. Killian, K. Hansen and M. Toumi (2009). Predictors of employment status change over 2 years in people with schizophrenia living in Europe. Epidemiologia e psichiatria sociale, 18(04): 344-351.

Milton, A., Parsons, N., Morant, N., Gilbert, E., Johnson, S., Fisher, A., Singh, S., Cunliffe, D. and S. Marwaha (2015). The clinical profile of employees with mental health problems working in social firms in the UK. Journal of Mental Health, 24(4): 242-248.

Nabdel, Y., N. Pourafkary and H. Dadashzadeh (2002). A six year follow - up study of schizophrenic patients admitted in Ta-briz mental hospital. Medical Journal of Tabriz University of Medical Sciences 54: 53-53

Ohaeri, J. U. (2001). Caregiver burden and psychotic patients' perception of social support in a Nigerian setting. Social Psychia-try and Psychiatric Epidemiology, 36(2): 86-93.

Rosso, B. D., K. H. Dekas and A. Wrzesniewski (2010). On the meaning of work: A theoretical integration and review. Research in organizational behavior, 30: 91-127. Tse, S. and M. Yeats (2002). What helps people with bipolar affective disorder succeed in employment: A grounded theory ap-proach. Work, 19(1): 47-62. PMid:12454350 Van Wijngaarden, B., Schene, A. H., Koeter, M., Vázquez-Barquero, J. L., Knudsen, H. C., Lasalvia, A., \& McCRONE, P. (2000). Caregiving in schizophrenia: 
47. Families 'experiences to Find a Job for Relatives ...

development, internal consiconsistency and reliability of the Involvement evaluation ques-tionnaire-European version. The British Journal of Psychiatry, 177(39), s21-s27.

Villotti, P., Corbière, M., Fossey, E., Fraccaroli, F., Lecomte, T. and C.Harvey( 2017). Work accommodations and natural sup-ports for employees with severe mental illness in social businesses: An international comparison. Community mental health journal, 53(7):864-870.
Whiston, S. C. and B. K. Keller (2004). The influences of the family of origin on career development a review and analysis. The Counseling Psychologist, 32(4): 493-568.

Woodside, H., L. Schell and J. Allison-Hedges (2006). Listening for recovery: The vocational success of people living with men-tal illness. Canadian Journal of Occupational Therapy, 73(1): 36-43. 


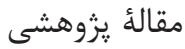 \\ تجارب خانوادهها در يافتن شغل براى بستخان مبتلا به اختلالات روانى شديد در ايران}

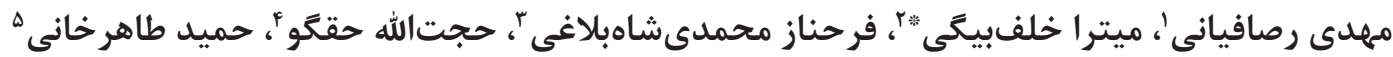

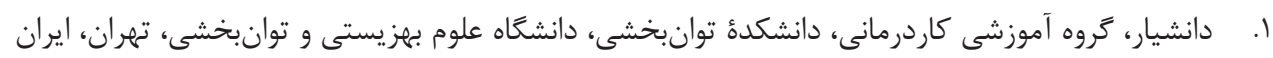

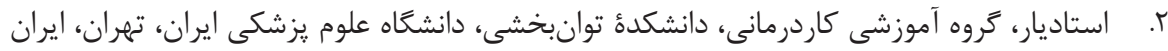

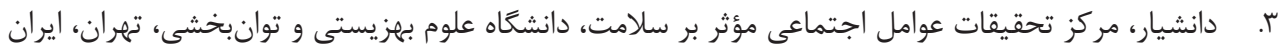

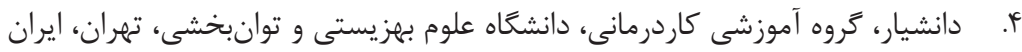

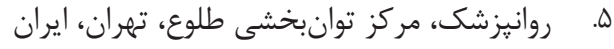

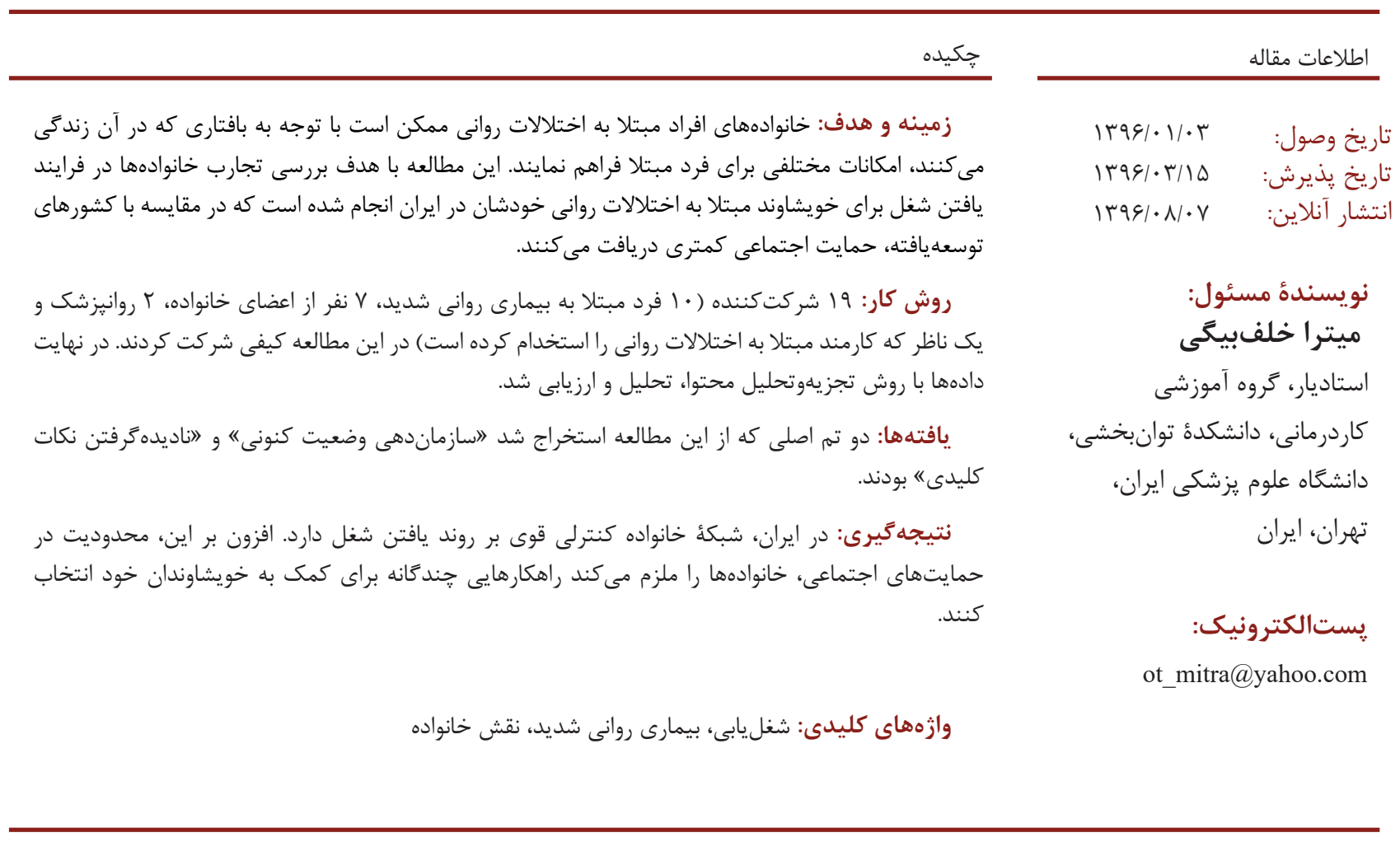

